\title{
Seed Geometry in the Arecaceae
}

\author{
Diego Gutiérrez del Pozo ${ }^{1}$, José Javier Martín-Gómez ${ }^{2}{ }^{\circledR}$, Ángel Tocino ${ }^{3} \mathbb{C}$ and \\ Emilio Cervantes $2, *$ (1)
}

1 Departamento de Conservación y Manejo de Vida Silvestre (CYMVIS), Universidad Estatal Amazónica (UEA), Carretera Tena a Puyo Km. 44, Napo EC-150950, Ecuador; dgutierrez@uea.edu.ec

2 IRNASA-CSIC, Cordel de Merinas 40, E-37008 Salamanca, Spain; jjavier.martin@irnasa.csic.es

3 Departamento de Matemáticas, Facultad de Ciencias, Universidad de Salamanca, Plaza de la Merced 1-4, 37008 Salamanca, Spain; bacon@usal.es

* Correspondence: emilio.cervantes@irnasa.csic.es; Tel.: +34-923219606

Received: 31 August 2020; Accepted: 2 October 2020; Published: 7 October 2020

\begin{abstract}
Fruit and seed shape are important characteristics in taxonomy providing information on ecological, nutritional, and developmental aspects, but their application requires quantification. We propose a method for seed shape quantification based on the comparison of the bi-dimensional images of the seeds with geometric figures. $J$ index is the percent of similarity of a seed image with a figure taken as a model. Models in shape quantification include geometrical figures (circle, ellipse, oval ... ) and their derivatives, as well as other figures obtained as geometric representations of algebraic equations. The analysis is based on three sources: Published work, images available on the Internet, and seeds collected or stored in our collections. Some of the models here described are applied for the first time in seed morphology, like the superellipses, a group of bidimensional figures that represent well seed shape in species of the Calamoideae and Phoenix canariensis Hort. ex Chabaud. Oval models are proposed for Chamaedorea pauciflora Mart. and cardioid-based models for Trachycarpus fortunei (Hook.) H. Wendl. Diversity of seed shape in the Arecaceae makes this family a good model system to study the application of geometric models in morphology.
\end{abstract}

Keywords: circle; ellipse; lens; morphology; oval; seed shape; superellipse

\section{Introduction}

The Arecaceae Schultz Sch. (Palmae nom. cons.) is a unique family in the order Arecales, class Monocotyledoneae. It includes about 2600 species grouped in 181 genera of climbers, shrubs, and tree-like and stemless plants, all commonly known as palms, with a worldwide distribution in tropical and subtropical regions. Economically important species are the oil palm (Elaeis oleifera [Kunth] Cortes ex Prain), the coconut palm (Cocos nucifera L.), the date palm (Phoenix dactilifera L.) Other species in this family are the most used by local people in many tropical places like the Amazonian basin, with a great variety of applications [1-6]. It is remarkable that whole human communities, particularly in the tropics, depend on palms for their survival [1,6]. Trachycarpus fortunei (Hook.) H.Wendl. and Chamaerops humilis L. are frequently used as ornamentals in temperate zones in Mediterranean countries for their resistance to extreme temperatures.

The Arecaceae form a monophyletic group among the monocotyledons as supported by both molecular and morphological data that, in recent years, have integrated much information from DNA sequencing. Current taxonomy presents five subfamilies (Calamoideae, Nypoideae, Coryphoideae, Ceroxyloideae, and Arecoideae) divided into tribes and subtribes [1]. Table 1 shows the distribution of tribes within subfamilies and representative examples of genera. The largest subfamily, the Arecoideae, contains 106 genera grouped into 14 tribes, of which the largest, the Areceae is formed by 11 subtribes 
that receive their names from the respective genera (Archontophoenicinae, Arecinae, Basseliniinae, Carpoxylinae, Clinospermatinae, Dypsidinae, Linospadicinae, Oncospermatinae, Ptychospermatinae, Rhopalostylidinae, and Verschaffeltiinae), plus an additional group of ten unplaced genera (Bentinckia, Clinostigma, Cyrtostachys, Dictiosperma, Dransfieldia, Heterospathe, Hydriastele, Iguanura, Loxococcus, and Rhopaloblaste).

Table 1. A summary of the taxonomy of the Arecaceae. Subfamilies Calamoideae, Nypoideae, Coryphoideae, Ceroxyloideae, and Arecoideae divided into tribes. The number of genera in each subfamily and tribe is given between parentheses. Some examples of genera in each of the tribes are shown. Data adapted from [1].

\begin{tabular}{|c|c|c|}
\hline Subfamilies & Tribes & Genera \\
\hline \multicolumn{3}{|l|}{ I. Calamoideae (21) } \\
\hline & Eugeissoneae (1) & Eugeissona \\
\hline & Lepidocaryae (7) & Oncocalamus, Eremospatha, Laccosperma, Raphia \\
\hline & Calameae (13) & Calamus, Retispatha, Ceratolobus \\
\hline II. Nypoideae (1) & & Nypha \\
\hline \multicolumn{3}{|l|}{ III. Coryphoideae (46) } \\
\hline & Sabaleae (1) & Sabal \\
\hline & Cryosophileae (10) & Coccothrinax, Hemithrinax, Leucothrinax, Thrinax \\
\hline & Phoeniceae (1) & Phoenix \\
\hline & Trachycarpeae (18) & Chamaerops, Guihaia, Trachycarpus, Rhapis \\
\hline & Chuniophoeniceae (4) & Livistona, Licuala, Johannesteijsmannia \\
\hline & Caryoteae (3) & Caryota, Arenga, Wallichia \\
\hline & Corypheae (1) & Corypha \\
\hline & Borasseae (8) & Bismarckia, Lodoicea, Borassodendron, Borassus \\
\hline \multicolumn{3}{|l|}{ IV. Ceroxyloideae (8) } \\
\hline & Cyclospatheae (1) & Pseudophoenix \\
\hline & Ceroxyleae (4) & Ceroxylon, Juania, Oraniopsis, Ravenea \\
\hline & Phytelepheae (3) & Ammandra, Aphandra, Phytelephas \\
\hline \multicolumn{3}{|l|}{ V. Arecoideae (106) } \\
\hline & Iriarteeae (5) & Iriartea \\
\hline & Chamaedoreae (5) & Chamaedorea \\
\hline & Podococceae (1) & Podococcus \\
\hline & Oranieae (1) & Orania \\
\hline & Sclerospermeae (1) & Sclerosperma \\
\hline & Roystoneeae (1) & Roystonea \\
\hline & Reinhardtieae (1) & Reinhardtia \\
\hline & Cocoseae (18) & Cocos, Jubaea, Bactris, Elaeis \\
\hline & Manicarieae (1) & Manicaria \\
\hline & Euterpeae (5) & Hyospathe, Euterpe \\
\hline & Geonomateae (6) & Asterogyne, Geonoma \\
\hline & Leopoldiniaeae (1) & Leopoldinia \\
\hline & Pelagodoxeae (2) & Pelagodoxa, Sommieria \\
\hline & Areceae (58) & $\begin{array}{l}\text { Archontophoenix, Areca, Basselinia, Carpoxylon, } \\
\text { Clinosperma, Dypsis, Linospadix, Oncosperma, } \\
\text { Ptychosperma, Rhopalostylis, Verschaffeltia, }\end{array}$ \\
\hline
\end{tabular}

Based on the utility of palms in industry at both subsistence and world market levels, the Arecaceae has been reported to be the third family in applied importance in the Plant Kingdom following the Poaceae and the Fabaceae [5]. Detailed analyses of fruit and seed morphology in this family may provide valuable information.

\section{Seed Morphology in the Arecaceae}

The seeds of the Arecaceae are varied in size ranging from the small size of Prestoea Hook., a few millimeters in length, to the largest seeds of all plants weighing up to $25 \mathrm{~kg}$ : The "coco de 
mer" (Lodoicea maldivica [J. F. Gmelin] Persoon). The size and shape of fruits and seeds correspond to a diversity of types of dispersion, often in water or by zoochory by a variety of animals [6-10], with a predominance of the circular, ellipsoid, and oval morphology [1,11]. The combinations of fibrous mesocarps and hard endocarps enclosing a cavity made of the fruits of Cocos nucifera L. (Cocoseae, Arecoideae), L. maldivica (Borasseae, Coryphoideae), and other species, adaptations to floating in sea water, while other fruits have fleshy mesocarps and brightly colored epicarps attractive to mammalians such as civets (Caryota maxima Blume; Arenga pinnata [Wurmb] Merr. and Pinanga coronata Blume), gibbons (Arenga obtusifolia Mart.), coyotes (Washingtonia spp. H. Wendl.), elephants (Hyphaene Gaertn. and Borassus L.), and agoutis (Socratea H. Karst) [1,6-10,12]. In the large Amazonian palms, once ripe, some of the fruits fall and are consumed by peccaries (Tayassu pecari) and species of rodents such as the guantas (Cuniculus paca), guatusas (Dasyprocta spp.), and coatis (Nasua spp.), which disperse their seeds and bury them at times of abundance [6]. Other fruits are food for birds like the Malabar hornbills (Korthalsia Blume) and parrots, or fishes [9]. The fruits of Prestoea ensiformis (Ruiz \& Pav.) H.E. Moore or Astrocaryum chambira Burret fall by their own weight and once on the ground are eaten and their seeds transported by rodents, tapirs, and wild boar [6]. For reviews on animal-mediated seed dispersal in palms see $[10,13]$.

In some palms, it is impossible to distinguish between the endocarp and the seed. In many species of Licuala (Chuniophoeniceae, Coryphoideae), such as L. spinosa, L. glabra, and L. grandis, the former is very thin and crustaceous. In other species, it is very thick and hard, e.g., in Eugeissona (Calamoideae), Nypa (Nypoideae), Borasseae, a few species of Licuala (e.g., L. beccariana), Ptychococcus, the Cocoseae (Arecoideae), and the Phytelepheae (Ceroxyloideae) [1]. Three types of endocarp have been described [14]: the coryphoid type differentiates from the inner part of the fruit wall; the chamaedoreoid type forms solely from the locular epidermis; the cocosoid-arecoid type develops from the locular epidermis, bundle sheaths, and intervening parenchyma. Different developmental patterns, described as continuous, discontinuous, and basipetal, are correlated with these endocarp types [1].

Numerous taxonomic groups in the Arecaceae received their Latin names according to characteristics of their fruits and seeds (size, hardness ... ). Table 2 contains examples of the names that refer to seed or fruit shape. For example, the prefix Ptychos, meaning folding or doubled gives the name of two genera Ptychococcus and Ptychosperma (Figure 1), both in the sub-tribe Ptychospermatinae, in the sub-family Areceae. Seedling morphology and anatomical studies have been the basis for classification in the family [15]; nevertheless, seed morphology specifically has not received much attention.

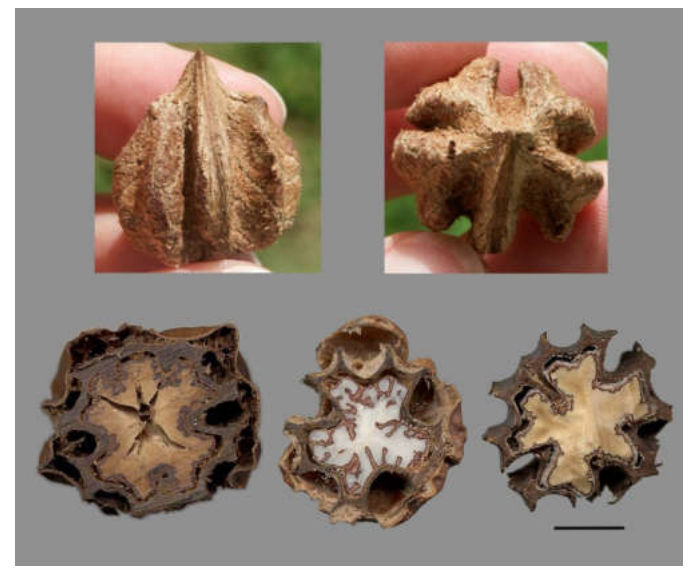

Figure 1. Ptychococcus species owe their name to the morphological properties of their seeds. Ptychos means folding or doubled seed (surface). Images: Ptychococcus paradoxus. Above: Two views of the seed. Below: Transversal sections in three seeds of different origins. Bar represents $1 \mathrm{~cm}$. Photos courtesy of Scott Zona. 
Table 2. Some of the names in the taxonomy of the Arecaceae are related to morphological characteristics of their fruits and seeds.

\begin{tabular}{cc}
\hline Name & Meaning \\
\hline Actinorhytis & Radiate wrinkled (seed) \\
Astrocaryum & Star-like pattern of fibers around endocarp pores \\
Attalea amygdalina & Almond-shaped fruits \\
Barcella & Little boat-shaped (seed) \\
Calamus pycnocarpus & Thick fruit \\
Carpoxylon & Thick, woody fruit \\
Ceratolobus & Lobate horn-shaped fruit \\
Chelyocarpus & Turtle carapace-shaped fruit \\
Clinosperma, Clinospermatinae & Bent seeds (asymmetric) \\
Cyphosperma & Gibbous seeds \\
Chrysalidocarpus, Chrysalidosperma & Chrysalid-like fruit (seed) \\
Daemonorops oxycarpa & Sharp, pointed (fruit) \\
Dictyocaryum & Net of branches in the fruit \\
Dictyosperma & Net of branches in the seed \\
Eremospatha macrocarpa & Large fruit \\
Kentiopsis oliviformis & Olive shaped \\
Kentiopsis pyriformis & Pear shaped \\
Laccosperma & Seed with a hole or pit \\
Lepidocaryum & Fruit with scales \\
Lithocarpos cocciformis & Fruit hard and round \\
Lytocarium & Loose fruit \\
Nephrosperma & Kidney-shaped seeds \\
Oncosperma, Oncospermatinae & Humped or swollen seed \\
Pholidocarpus & Fruit with scales \\
Podococcus Podococceae & Foot shaped fruit \\
Ptychococcus Ptychosperma, Ptychospermatinae & Folding or doubled seed surface \\
\hline
\end{tabular}

The shapes of many seeds in the Arecaceae are often described as circular, ellipsoidal or elliptic, globose, ovoid, ovoidal, piriform, or rounded, including double adjectives such as "irregularly globose" or "broadly ovoid" [1]. A conclusion from a review of the literature is that a large proportion of species in this family have seeds resembling spheres, ellipsoids, and ovoids, but in general, the descriptions lack definition and are far from seed shape quantification. On the other hand, in regions with a great diversity of palms, such as the Amazon basin, most of the vegetative parts are difficult to access, while the seeds, due to the hardness of the endocarp, last for some time under the producing tree, being easy to find. In consequence, seed structure is often the key to the identification of palm species in the field.

Geometric models can be defined that adjust to the shapes observed making it possible to give accurate morphological descriptions of seed shape for a number of species, as well as the quantification of shape by comparison between the seed image and the model. The possibility of a model depends on the uniformity of seed shape in samples of a given species. Only when the shape is relatively constant, it is possible to describe it by means of a geometric model. Difficulties may arise from developmental aspects.

The shape is the result of a growth process and, in the same plant, or even in the same fruit, there may be differences in seed shape depending on many factors such as the developmental status, the type of inflorescence, the position of the seed in the plant or the fruit, and depending on the type of fruit. The seeds may form aggregates in the same fruit, such as Camellia japonica (Theaceae), Swietenia mahogany Jacq. (Meliaceae), Eucalyptus sp. L'Hér. (Myrtaceae), and Peganum harmala L., in the Nitrariaceae [11]. In the Arecaceae, this occurs in diverse genera (Latania, Phytelephas, Salacca ... ), and in the case of Eremospatha macrocarpa H. Wendl. (Lepidocaryae, Calamoideae), results in three morphological types having respectively the shape of $1 / 3$ of a sphere, hemispherical or ellipsoidal depending on the number of seeds developing simultaneously in a fruit [1]. 
Shape is the tridimensional result of complex developmental processes, but the description of it is based on particular aspects. Bi-dimensional images of seeds are often similar to geometric figures that can be used as models. To find a model, the images of different seeds must be taken from a similar perspective to avoid differences in orientation and maximize similarity. The overall shape of the seed (elongated, thinner, or thicker in a different position) and anatomical points (hilium, germination pore, ventral groove) can be references for orientation. Slight changes in orientation can give different images (Figure 2).

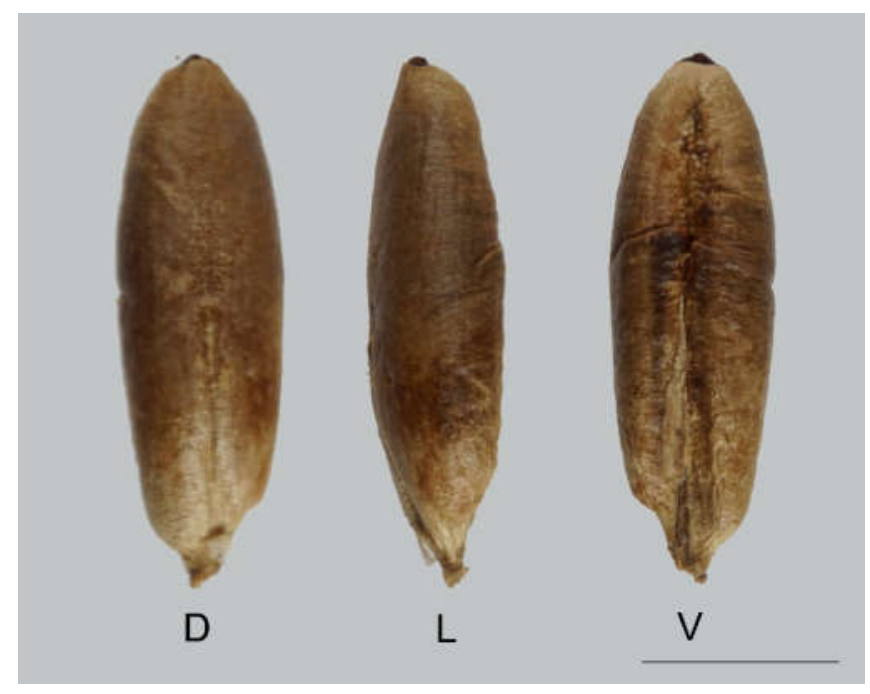

Figure 2. Seeds of Phoenix dactilifera L. in three views: dorsal (D), lateral (L), ventral (V). A groove is visible in the ventral side, opposed to the germination pore in a dorsal position. Bar equals $1 \mathrm{~cm}$.

\section{Geometric Models: Definition and Application}

\subsection{A Conceptual Aspect}

In this work, the shape of seeds will be related to geometric figures in a plane (bi-dimensional). In the literature, it can be seen that some of the adjectives used for shape description are applied to different objects: two-dimensional images of plane objects, three-dimensional objects, and their contours. This is a drawback because the same word has a different meaning when applied to each case. In other cases, different terms apply to precise, well-defined objects. For example, ovoid, or ovoidal refers to three-dimensional objects, while an oval is a bi-dimensional, plane figure. An important aspect of morphology is to define the object we work with; and a second aspect, not less important, is to define also the point of view we adopt for this object. In the description of seed shape, we consider a bi-dimensional approach easier and more straightforward than a tri-dimensional one. For example, to compare a seed with a sphere (3D) is much more difficult than to compare the image of that seed with a circle (2D). In addition, some of the models for the comparison of tri-dimensional objects are not sufficiently defined; for example, reniform means kidney-shaped, but a kidney is not an object described with precision; globose and globular mean approximatively rounded, but in a vague sense, not indicating similarity to any well-described figure.

Computer-assisted methods allow the measurements of multiple magnitudes of objects, but often the measurements are made in two dimensions [16,17]. Thus, when applying artificial vision methods [18], figures are represented by the coordinates of a set of points in the plane, that can be submitted to algebraic transformations and compared with a set of figures in databases. Plant organs, in general, and seeds in particular, have a similarity with geometric objects, and the comparison between both $2 \mathrm{D}$ images, the plant structure, and the geometric model, provides a direct method for the quantitative description of shapes. 


\subsection{J Index, a Magnitude in Seed Morphology}

To be useful for classification, the geometric description of seed shape must be open to quantification. Comparing the shape of seeds (outline of seed images) to geometric figures permits a precise quantification of seed shape, and in this condition, shape description is independent of size. We have established a method based on the comparison of the bi-dimensional images of seeds with geometric figures by the calculation of $J$ index $[19,20]$. $J$ index is the percent of similarity between two plane figures: the seed image and the geometric model [19-27]. It ranges between 1 and 100 and is a measure of shape, not size. In consequence, the adjectives used to define the shapes of seeds are based on the names of well-defined geometric figures. The morphological type of seeds, corresponding to a geometric model, is a characteristic of the species, and more rarely of the genus. In some genera, such as Acoelorrhaphe, Copernicia, Sabal, and others, there may be a predominance of the circular type, but several observations with statistical support need to be done for each species. With this method, we can get information about seed morphology in wild species or cultivated varieties [27], as well as on aspects of seed shape related to taxonomy and life forms [28-30] or habitat [31].

\subsection{Calculation of J Index}

$J$ index measures the percent of similarity of a seed image with the geometric model. To calculate $J$ index in each seed image a series of graphic compositions are elaborated with Corel PHOTO-PAINT $\mathrm{X} 7$, in which the outline of the geometric model (circle, ellipse, or any other) is superimposed to the seed image, searching a maximum adjustment between both shapes, the seed, and the model. For each sample three graphic documents are kept: (1) a file in PSD format with the seed image and the geometric figure adapted to it, in which it is possible to make changes and corrections; (2) a file in JPG format with the geometric models in white, to discriminate between shared and total areas and thus, obtain the values of the area shared between the geometric figure and the seed image (S; Figure 3A,C), and (3) another file in JPG format with the geometric models in black, to obtain total area (T; Figure 3B,D). Representative images of (2) and (3) are shown in Figure 3 taking as an example the seed of Geonoma congesta H. Wendl. ex Spruce.

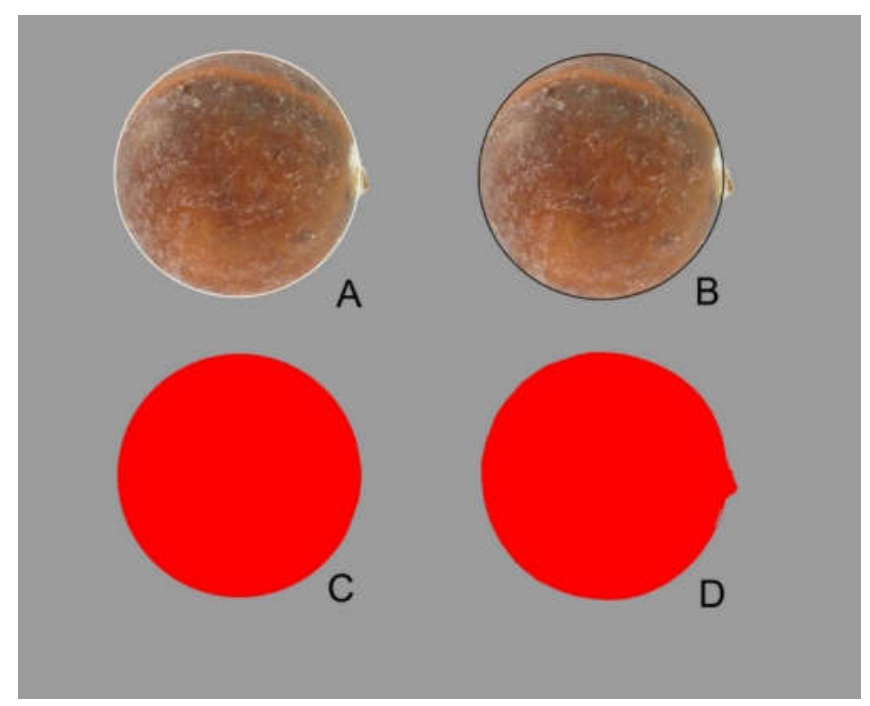

Figure 3. View of a seed of Geonoma congesta. (A) With white circle superimposed; (B) with a black circle superimposed; (C) The area shared (S) between the seed image and the geometric model for calculation with Image J. (D) Total area (T) for calculation in Image J. J index is the ratio S/T $\times 100$. In this example, $J$ index $=96.1$. Image of G. congesta courtesy of Steven Paton. Taken from https://stricollections.org/.

It can be observed that the size of the red-figure represented in $\mathrm{D}$ (Total area, $\mathrm{T}$ ) is slightly superior to the represented in $C$ (Shared area, S). $J$ index is the ratio $S / T \times 100$. 


\section{Geometric Models: Definition of the Models}

This section describes the geometric figures that are models in the description of seeds in the Arecaceae. Most of the descriptions are accompanied by a formula; these algebraic formulae correspond to the equation in Cartesian coordinates of the curve that delimits the figure (notice that in almost all cases the same name is used for the curve and the figure). The first groups belong to elementary geometry, while the latter groups include a set of figures constructed as graphical representations of algebraic equations. In general, we use the traditional terminology, but a particular case deserves attention. An oval is a convex figure limited by a $C^{2}$ closed curve. Convex means that any pair of its points are joined by a segment contained in the figure. The $\mathrm{C}^{2}$ property or continuous second degree of smoothness ensures the continuity of the curvature, in particular, the absence of "peaks". In this sense, many common geometric figures are ovals (circles, ellipses ... ). On the other hand, the word "oval" derives from the similarity with an egg shape (ovus in Latin), and this invites to its utilization in a restrictive sense, that will be used in this work, excluding, e.g., circles and ellipses.

\subsection{Circle}

The circle [32], the figure delimited by a circumference, is defined, according to Euclid (Book 1 Definition 15):

"A circle is a plane figure bounded by one curved line, and such that all straight lines drawn from a certain point within it to the bounding line, are equal. The bounding line is called its circumference and the point, it's center."

A circumference (centered at the origin) of radius $r$ is represented by the expression:

$$
x^{2}+y^{2}=r^{2}
$$

\subsection{Ellipse}

The ellipse [33] is "a curve surrounding two focal points, such that for all points on the curve, the sum of the two distances to the focal points is a constant". An ellipse (centered at the origin) is represented by the formula:

$$
\frac{x^{2}}{a^{2}}+\frac{y^{2}}{b^{2}}=1
$$

where $a, b>0$ represent the semi-major and semi-minor axis, respectively. The circumference is a particular ellipse in which the two focal points coincide; in this case, $a=b=r$.

\subsection{Oval}

In our restricted sense, an oval is a curve resembling the silhouette of an egg. Unlike ellipses, ovals have only a symmetry axis [34]. Ovals can vary depending on their construction as well as on their degree of symmetry, going from figures close to ellipses to others with a remarked single symmetry. The family of ovals used in this work have the equation

$$
\left(x^{2}+a y^{2}\right)^{2}=b x^{3}+c x y^{2}
$$

with $a>0 ; b, c$ constants.

\subsection{Lemniscate}

A lemniscate (of Bernoulli) [35] is the locus of points whose product of distances from two fixed points (called foci) equals a constant. A lemniscate is given by the equation

$$
\left(x^{2}+y^{2}\right)^{2}-2 a^{2}\left(x^{2}-y^{2}\right)=0
$$


where $a$ is a real constant. By simple algebra, the equation for a half lemniscate is obtained as

$$
y^{2}=\sqrt{a^{4}+4 a^{2} x|x|}-a^{2}-x|x|
$$

\subsection{Superellipse}

Superellipses [36] can be seen as intermediate curves between an ellipse and its circumscribed rectangle. They are determined by the equation:

$$
\left|\frac{x}{a}\right|^{p}+\left|\frac{y}{b}\right|^{p}=1
$$

with $p>2$. In particular, for $a=b$ squared circles are obtained.

\subsection{Cardioid and Derivatives}

The cardioid [37] has the Cartesian equation:

$$
\left(x^{2}+y^{2}+a x\right)^{2}=a^{2}\left(x^{2}+y^{2}\right)
$$

with $a>0$. It has been used as a model for seed morphology in model plants $[22,23]$ and it adjusts well to seeds of many species in diverse taxonomic groups [28,30,31].

\subsection{Lens}

A lens [38] is a convex region formed as the intersection of two circular disks (when one disk does not completely enclose the other). If the two circles that determine a lens have an equal radius, it is called a symmetric lens, otherwise, it is an asymmetric lens. The Vesica piscis ("fish bladder") is a special type of symmetric lens formed with circles whose centers are offset by a distance equal to the circle radii [39]. The 3D solid obtained rotating a lens around the axis through its tips is called a lemon.

\subsection{Waterdrop}

In the description of seed shape, it may be useful to modify geometric figures to obtain better adaptations to the bidimensional shape of seeds. For example, we obtained a figure resembling a water drop adapting the basis in the heart curve [40] to a circumference overlapping the maximum width of the curve. It can be seen as the joint graphical representation of the functions:

$$
f(x)=-\frac{2}{3}+\sqrt{36-x^{2}}+\frac{16}{3\left(2+x^{2}+|x|\right)} ; g(x)=-\frac{6}{11}-\sqrt{36-x^{2}}
$$

Derived from this combination (Model 4 in [25]), an elongated waterdrop can be obtained modifying the aspect ratio of the figure.

\section{Geometric Models: Examples in Different Species in the Arecaceae}

The following sections contain examples of seeds with the morphological types corresponding to the geometric models. Photographs corresponding to some of the examples are given in Figures 4-10 and a list of species for each type is provided in Table 3. Appendix A contains the sources of the images used in the Figures, while a Dataset has been published containing all the images used in this study (Supplementary Materials, doi:10.5281/zenodo.4009081). Chapter 6 discusses the relationships between morphological types and taxonomical groups. Seeds of a species can fit different models when observed from a different point of view, and for this reason, it is important to indicate the orientation in the images before proceeding to quantification with a given model. 


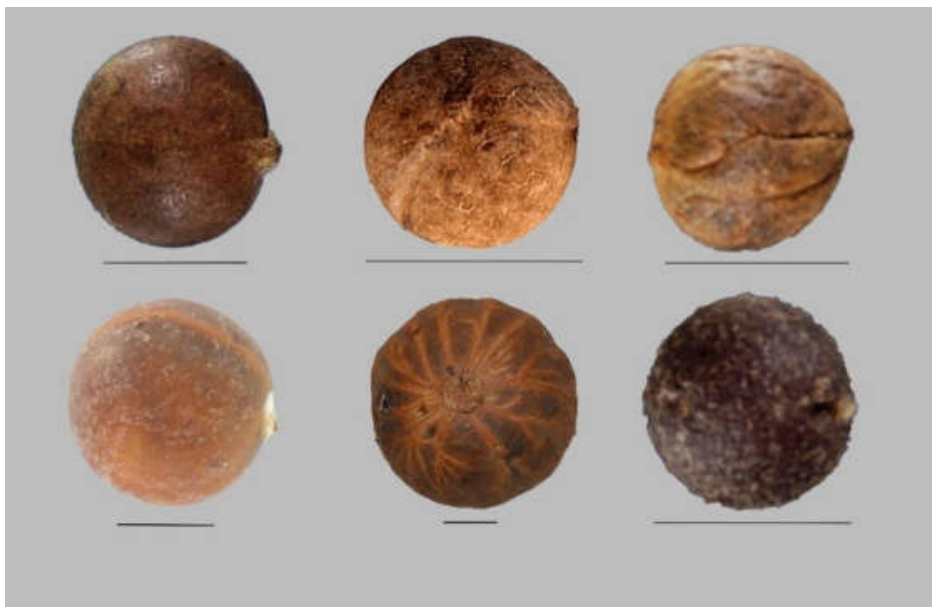

Figure 4. Representative examples of round seeds ( $\mathrm{index}$ values are indicated between parentheses). From left to right: Acoelorrhaphe wrightii (93.6), Acrocomia aculeata (95.7), Coccothrinax argentata (92.6), Geonoma congesta (96.1), Iriartea deltoideia (95.3), and Thrinax radiata (95.4). The seed of Iriartea deltoidea is oriented with the attachment of the peduncle in a frontal position. In the other seeds, the place of attachment of the peduncle is in a lateral position. Bars represent $0.5 \mathrm{~cm}$.

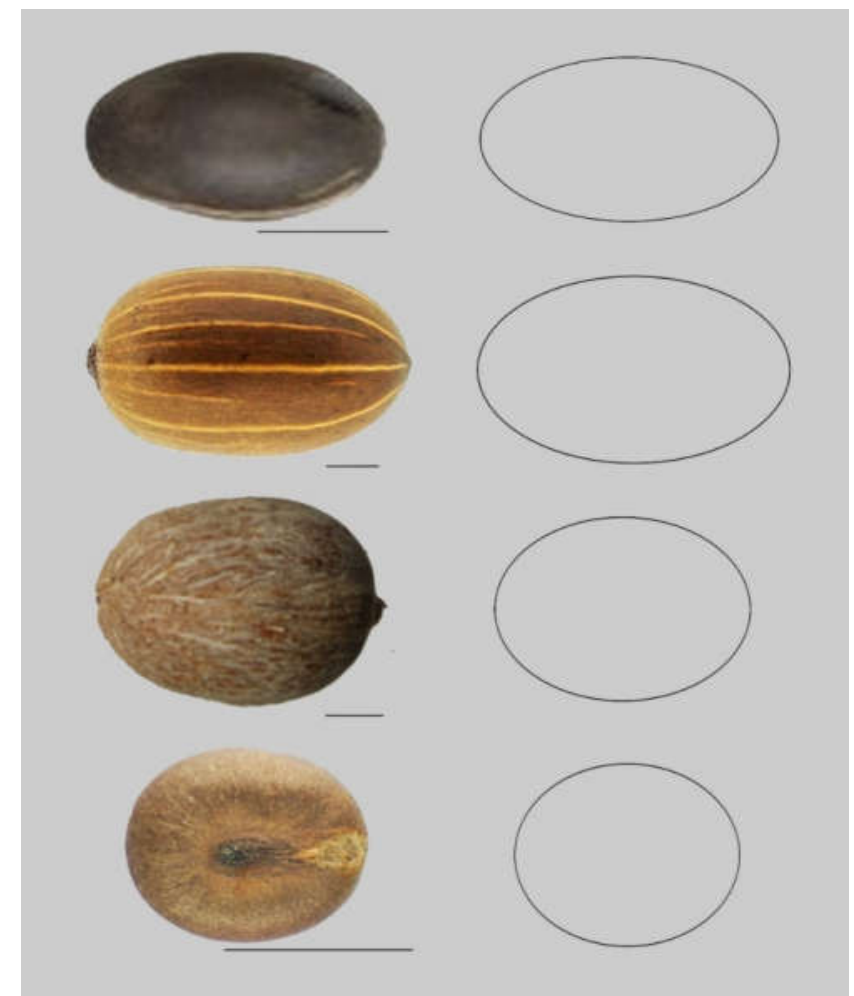

Figure 5. Representative examples of elliptic seeds with their respective models $(J$ index values are indicated between parentheses): Iriartella sp. (94.4), Socratea exorrhiza (91.6), Adonidia merrillii (92.0), and Washingtonia filifera (91.9). The seed of W. filifera (bottom) is oriented with the attachment of the peduncle in a frontal position while in the other three seeds the attachment of the peduncle is in a lateral position. Aspect ratio values for the ellipses are (from top to bottom): 1.8, 1.7, 1.4, and 1.2. Bars represent $0.5 \mathrm{~cm}$. 


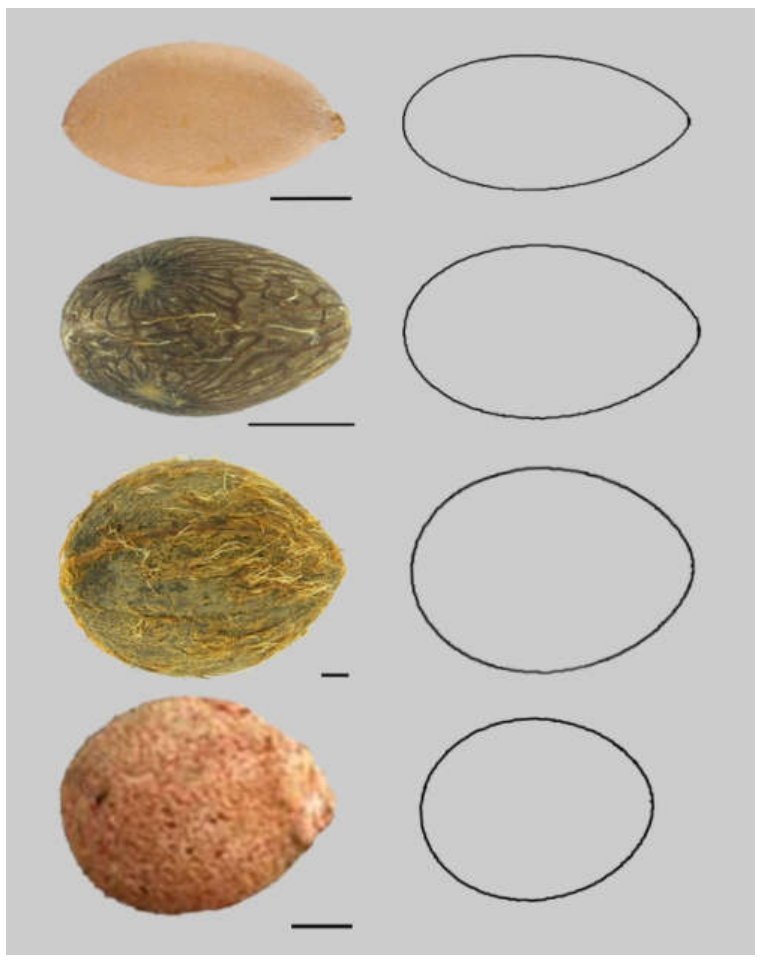

Figure 6. Representative examples of seeds, whose images adjust well to different ovals, ( $\mathrm{J}$ index values are indicated between parentheses). From top to bottom (more to less elongated): Serenoa repens (90.0), Desmoncus sp. (93.6), Astrocaryum standleyanum (91.5), and Medemia argun (92.1). The ovals correspond to the equations given in the text. Bars represent $0.5 \mathrm{~cm}$.

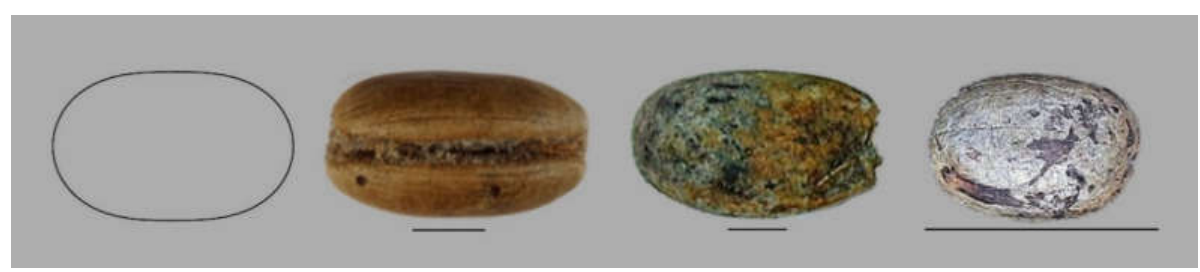

Figure 7. An example of the superellipse (model) and representative seeds adjusting to models in this family (between parentheses the values of $J$ index with this model): P. canariensis ( 92.15 is the mean value of 25 seeds), Welfia regia (92.6), and Raphia taedigera (90.0). Bars represent $0.5 \mathrm{~cm}$. The model is defined by Equation (6) with $a=3.6, b=2.2$, and $p=2.4$.

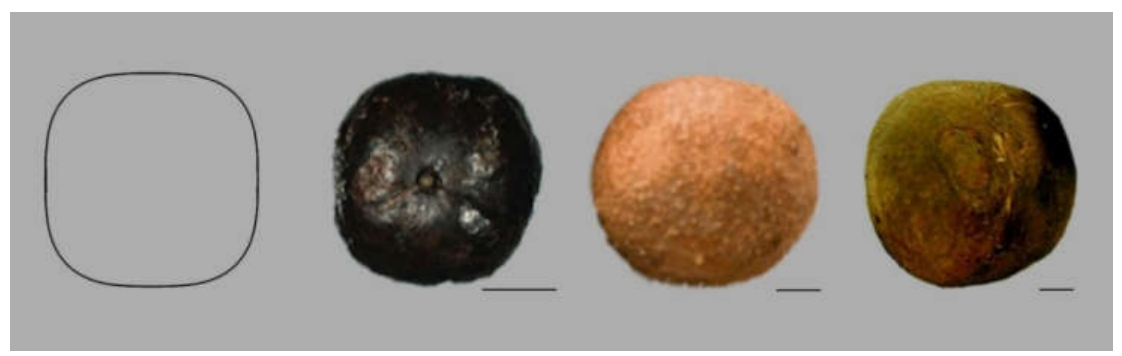

Figure 8. The squared circle (model) and representative examples of seeds adjusting to it (between parentheses the values of $J$ index with the respective models): Clinosperma macrocarpa (91.5), Johannesteijsmannia altifrons (92.4), and Mauritia flexuosa (92.0). In C. macrocarpa the seed is orientated with the stem end in a central position, while the other seeds present a side view. The model is defined by Equation (6) with $a=b=1$, and $p=3$. 

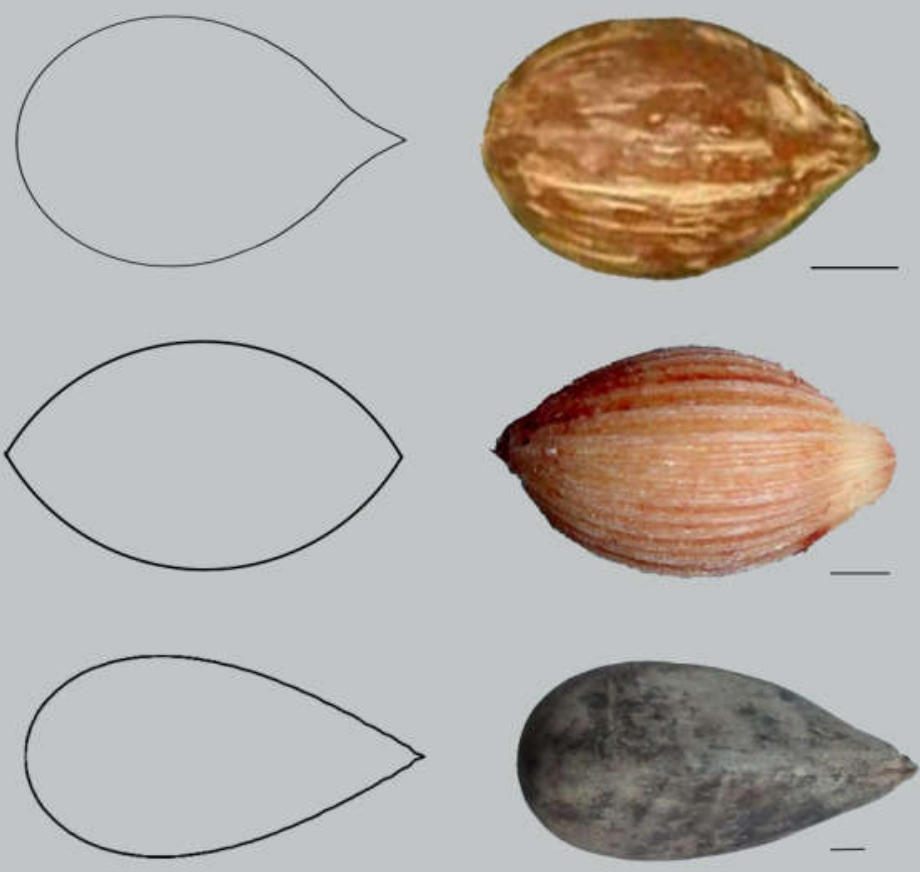

Figure 9. Water Drop, Lens, and Half Lemniscate with examples of seeds resembling each of the models (between parenthesis values of $J$ index with the respective model): Syagrus romanzoffiana (92.3, mean of three seeds), Asterogyne martiana (91.8), and Aphandra natalia (93.8). Bars represent $0.5 \mathrm{~cm}$.

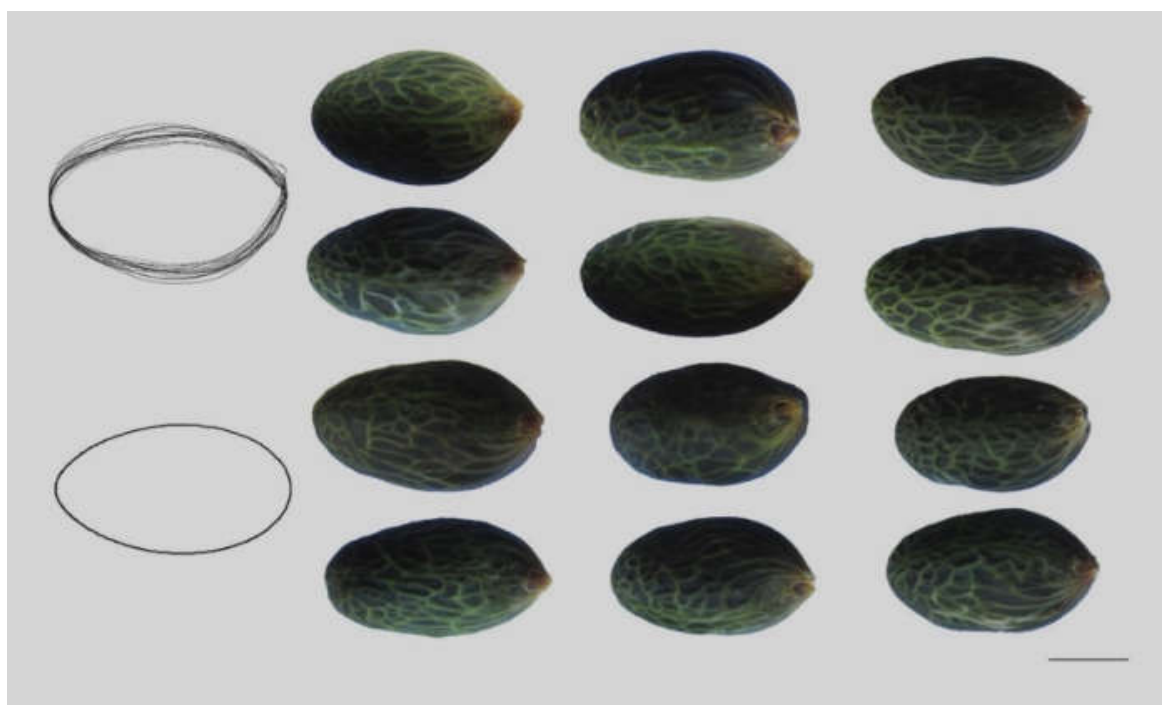

Figure 10. Seed shape quantification by an oval in Chamaedorea pauciflora. Left, above: Image with superimposed silhouettes of 12 seeds. Left, below: The model, an oval defined by the equation given in the text. The seed images used for seed shape quantification (comparison with the model) are in three columns and four rows. J index value (mean of 12 measurements) is 90.7 . Bar represents $0.5 \mathrm{~cm}$. 
Table 3. Geometric models with some representative examples of seeds for each morphological type.

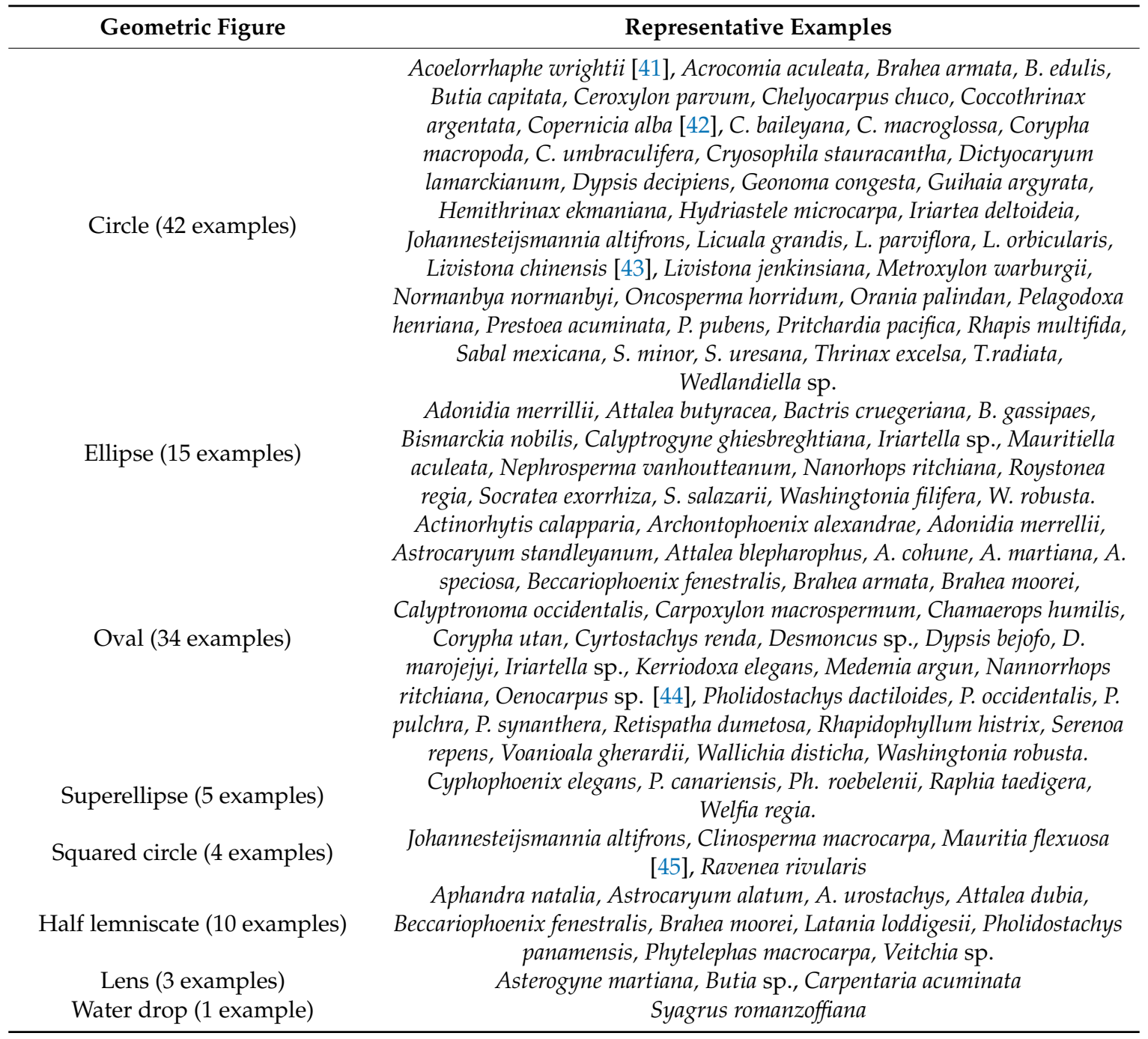

\subsection{Seeds That Project Circular Images}

Round seeds project circular images from any perspective. However, ellipsoidal and ovoidal seeds can also give circular images that are useful for species identification and classification. For an accurate description, the seed orientation has to be given and, in any case, values of $J$ index need to be obtained in a representative number of samples. Figure 4 shows representative examples of circular seeds: Acoelorrhaphe wrightii (Corypheae, Coryphoideae), Acrocomia aculeata (Cocoseae, Arecoideae), Coccothrinax argentata (Cryosophileae, Coryphoideae), Geonoma congesta (Geonomateae, Arecoideae), Iriartea deltoideia (Iriarteeae, Arecoideae), and Thrinax radiata (Cryosophileae, Coryphoideae). Other examples are also found in diverse sub-families and tribes (Table 3).

\subsection{Elliptical Seeds}

Ellipsoidal seeds give bi-dimensional images that vary from circular to elliptical, depending on the selected point of view. The elliptical shape is determined by the ratio between the major and minor axes (aspect ratio). Figure 5 shows representative examples of seeds whose images adjust well to ellipses of different values. These are Iriartella sp. and Socratea exorrhiza (Iriarteae, Arecoideae), Adonidia merrillii (Areceae, Arecoideae), and Washingtonia filifera (Corypheae, Coryphoideae). Other examples are also found in diverse sub-families and tribes (Table 3). 


\subsection{Seeds Resembling Ovals}

As was pointed out in Section 4.3, the oval has just one symmetry axis. A list of species whose seed images resemble ovals are given in Table 3. A useful mode to define the oval is by an algebraic formula, see, e.g., Equation (3). Figure 6 contains representative examples of oval seeds with their respective models: Serenoa repens (Corypheae, Coryphoideae), Desmoncus sp. (Cocoseae, Arecoideae), Astrocaryum standleyanum (Cocoseae, Arecoideae), and Medemia argun (Borasseae, Coryphoideae). Other examples are also found in diverse sub-families and tribes (Table 3).

The shape of the seeds represented in Figure 6 are ovals and all the curves representing them have been obtained with Equation (3) varying the parameters:

- Serenoa repens: $a=2 ; b=5 ; c=2.6$;

- Desmoncus sp.: $a=1.4 ; b=4.3 ; c=3$;

- Astrocaryum standleyanum: $a=1 ; b=4 ; c=3.3$;

- Medemia argun: $a=1 ; b=3.4 ; c=3.3$

Often the seeds of the different species in a genus have different morphological types, such as in Bactris, Brahea, Butia, Chamaedorea, Geonoma, and Pholidostachys. In some genera there is a considerable degree of variation in seed shape, for example, the seeds of Pholidostachys have ovoid shapes with varying degrees of polarity in a gradient in the direction from (acute) ovoid to ellipse (and circular):

$$
\text { P. panamensis }>\text { (P. synanthera, P. dactiliodes, P. occidentalis })>\text { P. pulchra (P. kalbreyeri) }
$$

Once a model has been proposed for a species or a population, the proposal has to be validated statistically. $T$-test allow us to validate the hypothesis that seed lots belong to a given morphological type. We consider that a seed population belongs to a given morphological type when the hypothesis test concludes that the mean $J$ index of the species is equal to or superior to 90 with a significance level of $95 \%$. An example is later given with seeds of Phoenix canariensis (Figure 7).

The transitions between related forms (Circle-Ellipse-Oval) are very subtle and many species have seeds of variable shape. A mixture of shapes of the main types may be observed in images containing multiple seeds of the following species: Actinorhytis calaparia, Aiphanes horrida, Archontophoenix alexandrae, Bismarckia nobilis, Brahea armata, Caryota maxima, Chamaedorea tuerkeimii, Chamaerops humilis, Corypha utan, Guihaya argyrata, Jubaeopsis caffra, Medemia argun, Nanorrhops ritchiana, and Washingtonia robusta.

\subsection{Seeds Resembling the Superellipse and Related Figures}

The superellipses and squared circles [36] are figures that, to our knowledge, have not yet been mentioned in the morphological description of seeds in the Arecaceae.

The squared circle may be considered as a particular case of the superellipse (Equation (6)). Figure 7 represents the superellipse and seeds representative of this morphological type. The seeds of P. canariensis (Phoeniceae, Coryphoideae), Welfia regia (Geonomateae, Arecoideae), and Raphia taedigera (Lepidocaryeae, Calamoideae) adjust to a superellipse. The hypothesis test done with 25 seeds (sample mean $=92.15$ ) concludes that the mean $J$ index of the population of $P$. canariensis from which the seeds were taken is equal or superior to 90 with a significance level of $99 \%$.

The seeds of Clinosperma macrocarpa (Areceae, Arecoideae), Johannesteijsmannia altifrons (Chuniophoeniceae, Coryphoideae), and Mauritia flexuosa (Lepidocaryeae, Calamoideae) and others (Table 3) adjust to a squared circle (Figure 8).

\subsection{Seeds Resembling Other Figures: Half Lemniscate, Lens and Waterdrops}

The figures of half lemniscate and waterdrops resemble elongated ovals with a peak in their apex. Depending on the degree of asymmetry perpendicular to the symmetry axis, the seeds resembling ovals may have shapes near to ellipses, such as Medemia argun or, on the other hand, be more asymmetric 
and divergent from the ellipse, such as Serenoa repens (see Figure 6). In other seeds there is still more asymmetry between the two poles, giving images similar to half lemniscate as in the case of some seeds of Aphandra natalia (Phytelepheae, Coryphoideae, Figure 9). Seeds of this type can be observed in other species such as Astrocaryum urostachis, Syagrus romanzoffiana and Beccariophoenix fenestralis (Cocoseae, Arecoideae), Phytelephas macrocarpa (Phytelepheae, Coryphoideae), Pholidostachys panamensis (Geonomeae, Arecoideae), and Wodyetia bifurcata (Areceae, Arecoideae).

Images of seeds of Asterogyne martiana (Geonomeae, Arecoideae) adjust well to a lens. This model may also be helpful in the quantification of some seeds in Butia sp. (Cocoseae, Arecoideae), Carpentaria acuminata (Areceae, Arecoideae), and others.

\section{Seed Shape Quantification by Comparison with an Oval in Chamaedorea pauciflora}

Figure 10 shows a sample of 12 seeds of Ch. pauciflora (Chamaedoreae, Arecoideae), with an image containing the sum of their profiles in a composed image and the model used for their quantification. The model is an oval (Equation (3) with values $\mathrm{a}=1, \mathrm{~b}=4, \mathrm{c}=3.3$ ). $J$ index value (mean of the measurements in the 12 images of Figure 10) is 90.7.

\section{Morphological Aspects of the Fruits and Seeds of Trachycarpus fortunei}

The fruits and seeds of $T$. fortunei (Trachycarpeae, Coryphoideae) adjust well to the cardioid or cardioid-related figures (Figure 11). The fruits with exocarp resemble a cardioid. Deprived of the pericarp, the seeds with endo- and mesocarps resemble a flattened cardioid. Finally, the seeds covered only by the endocarp resemble an open cardioid. The two cardioid-derived models were developed for the morphological analysis of diverse species of Silene L. (Caryophyllaceae). While the cardioid gave high values of $J$ index with many species, a flattened cardioid was the model for Silene latifolia Poir., while the open cardioid was better for Silene gallica L. [46].

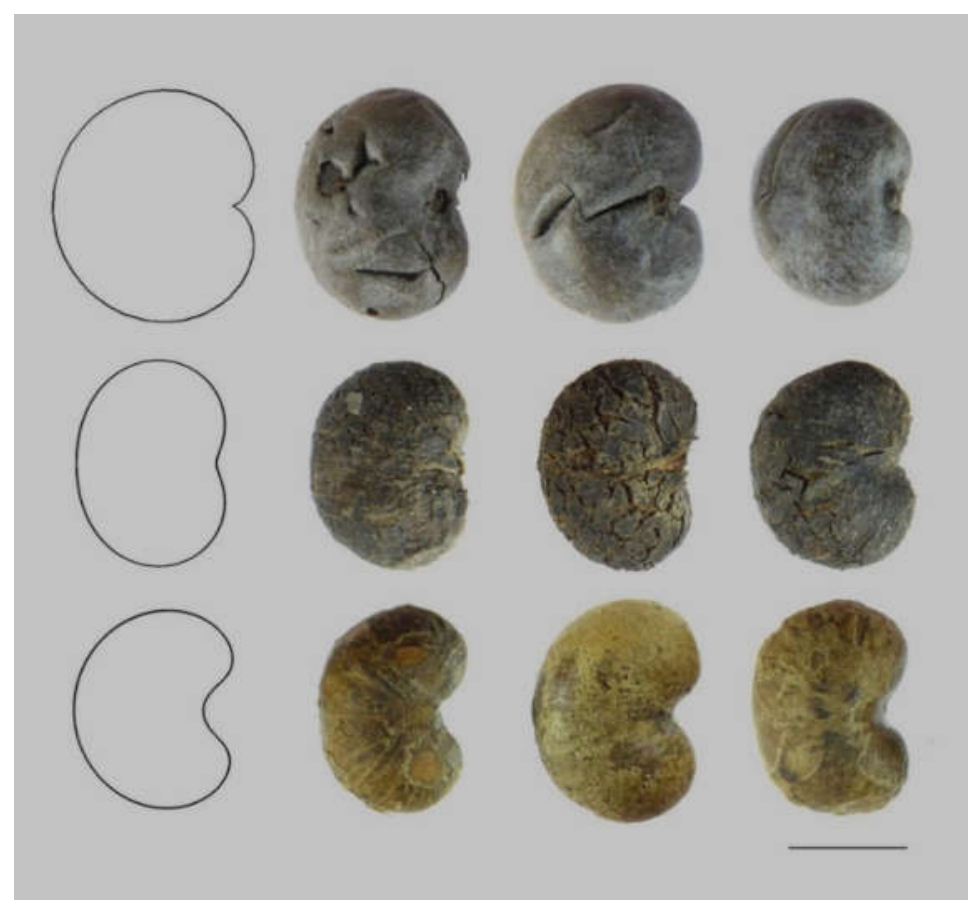

Figure 11. T. fortunei (between parenthesis values of $J$ index with the respective model). Top: Cardioid and images of three fruits (90.4). Middle row: Modified cardioid (flattened) and images of three fruits without exocarp (the outer, visible layer is the mesocarp) (92.1). Bottom row: Modified cardioid (open) and three seeds covered only by the endocarp (exocarp and mesocarp have been removed) (91). Bar represents $0.5 \mathrm{~cm}$. 


\section{Geometric Models in the Arecaceae: Relation with Anatomical Properties and Taxonomy}

The genera with apocarpic fruits tend to have their seeds more rounded or regularly-shaped. These include Nypa, and many genera in the Coryphoideae (Chamaerops, Chelyocarpus, Coccothrinax, Cryosophila, Guihaia, Hemithrinax, Itaya, Leucothrinax, Maxburretia, Rhapidophyllum, Rhapis, Schippia, Trachycarpus, Thrinax, Trithrinax, Zombia) [1,47]. Nevertheless, this is not a characteristic exclusive of the sub-family because rounded or regular seeds have been observed in other taxa, and both oval and elliptical seeds are frequent throughout all the family. Oval shaped, particularly elongated ovals, half lemniscates and lens-shaped seeds are frequent in the Arecoideae, but the type is also observed in the syncarpous clade of the subfamily Coryphoideae, that includes four tribes containing high diversity in seed size and shape: Borasseae, Corypheae, Caryoteae, and Chuniophoeniceae [48].

Quantification of seed shape is interesting at the species level to describe the characteristic morphology in those species that have regular shaped seeds, but it may also be interesting in species that have variable seeds to investigate the molecular basis of morphological types and the biological meaning of geometric forms, as well as to correlate them with other morphological features such as color, surface smoothness/roughness, and striation. For example, the seeds of 17 cultivars of Rubus sp. L. were classified recently based on the shape of the raphe: straight, concave, or convex. Cultivars within each group could be differentiated by seed shape, size, color, and seed-coat sculpturing [49].

Species of the Arecaceae have traditionally been recognized as important components of tropical forests, and six of the 10 most common tree species in the Amazon rain forest are palms [50]. Recent work based on massive information obtained by large data-sharing networks such as RAINFOR in South America and AfriTRON in Africa [51-53] points to an even more important role of palms in the Neotropics [54], suggesting that the knowledge of palm physiology, taxonomy and ecology will contribute to predict the evolution of the ecosystem under variable climatic conditions.

Computer programs for the identification of seeds by comparison with geometric figures may develop based on the comparison of in situ photographs with information stored in databases. The development of techniques and resources in seed morphology will also have applications in archaeology as both the remains of seeds and even populations of these plants are frequently found in archaeological sites [55].

The understanding of seed geometry may be at the basis of the knowledge of structural biology to which P.B. Tomlinson referred to in 1990 when he wrote: "Palms are not then merely emblematic of the tropics, they are emblematic of how the structural biology of plants must be understood before evolutionary scenarios can be reconstructed." ([56] quoted in [1]).

\section{Conclusions}

The morphology of the seeds in the Arecaceae has been reviewed. This family contains a remarkable amount of generic and specific names due to seed characteristics, and in particular, morphological attributes.

New models have been proposed and a series of rules is given to accurately describe seed shape in the species of the Arecaceae. First, for those species that have seeds of regular shape, a geometric model can be identified. The seeds are round or circular when the model is the circle for any view of the seeds. Ellipsoidal and ovoid seeds or can also give images similar to circles from certain perspectives. The model for ellipsoidal seeds is an ellipse that can be defined by the Aspect Ratio. A convenient way to define an oval as a morphological 2D model is by the corresponding algebraic equation.

Additional geometric figures, other than the circle, ellipses, and ovals, can be used as models to give precise descriptions of seed shape in some species. Thus, the superellipse and the squared circle are new models useful for many seeds of the Calamoideae (Lepidocaryum, Mauritia, Mauritiella, Korthalsia, Salacca), as well as species in the genus Phoenix (Phoeniceae, Coryphoideae). The fruits of T. fortunei adjust well to a cardioid and the seeds to modified cardioids. Half lemniscate is a useful model for species of Astrocaryum, Attalea, Beccariophoenix, Brahea, Lattania, Pholidostachys, Veitchia, and others. 
Lenses are good models for the description and quantification of seed shape in Asterogyne martiana, and most probably will be of application in other species as Butia sp. and Carpentaria acuminata.

Morphological types are varied and, for many species, there is not a clear pattern conserved in the majority of seeds that may be associated with a geometric figure. There is not an obvious relationship between the higher taxonomic divisions (subfamilies, tribes, and sub-tribes) and the models, although a trend is observed in the subfamily Coryphoideae with a high frequency of round seeds in genera with apocarpic fruits and oval, lemniscate-type seeds in the syncarpous clade of this subfamily.

Seed morphometry provides interesting tools for the identification of species in regions with a great diversity of palms, such as the Amazon basin. The seeds are critical structures in taxonomy in many cases where vegetative organs are similar among different species. In addition, thanks to their very resistant endocarp, seeds are easy to find and last a long time under the tree producer allowing differentiation up to the level of species in many instances.

The development of software of image identification based on geometric models may be an interesting contribution to future biodiversity studies.

Supplementary Materials: A Dataset has been published containing the web addresses for the images used in this study (Arecaceae. Sources of seed images in the web; https://zenodo.org/record/4009081; doi:10.5281/zenodo.4009081).

Author Contributions: Conceptualization, E.C.; methodology, J.J.M.-G.; software, J.J.M.-G, Á.T.; validation, D.G.d.P., J.J.M.-G., Á.T. and E.C.; investigation, D.G.d.P., J.J.M.-G., Á.T. and E.C.; resources D.G.d.P., J.J.M.-G., Á.T. and E.C.; data curation, D.G.d.P., J.J.M.-G and E.C.; writing-original draft preparation, E.C.; writing-review and editing, D.G.d.P., J.J.M.-G., Á.T. and E.C.; visualization, J.J.M.-G.; supervision, E.C. All authors have read and agreed to the published version of the manuscript.

Funding: This research received no external funding.

Acknowledgments: In this section, you can acknowledge any support given which is not covered by the author's contribution or funding sections. This may include administrative and technical support, or donations in kind (e.g., materials used for experiments).

Conflicts of Interest: The authors declare no conflict of interest.

\section{Appendix A. Web Sources of the Images Used in the Figures}

- $\quad$ Figure 1: Courtesy of Scott Zona

- $\quad$ Figure 2: Seed collection IRNASA-CSIC.

- Figure 3: Geonoma congesta seed image courtesy of Steven Paton

- Figure 4: Acoelorrhaphe wrightii: http://palmvrienden.net/gblapalmeraie/2017/06/27/acoelorrhaphewrightii/ Acrocomia aculeata: https://www.palmpedia.net/wiki/Acrocomia_aculeata Coccothrinax argentata: http://idtools.org/id/palms/palmid/factsheet.php?name=9413 Geonoma congesta: Steven Paton https://www.discoverlife.org/mp/20p?see=I_SP1454\&res=640 Iriartea deltoidea: http://www.belizehank. com/IMAGES/Palm\%20Seeds/Palm\%20seeds\%20alphabetical/Ireatea\%20deltoidea.jpg Thrinax radiata: https://idtools.org/id/palms/palmid/factsheet.php?name=Thrinax+radiata

- Figure 5: Iriartella sp.: http://www.plantsoftheworldonline.org/taxon/urn:lsid:ipni.org:names: 31287-1 Socratea exorrhiza: Steven Paton, https://www.discoverlife.org/mp/20p?see=I_SP3245\& res $=640$ Adonidia merrillii: Seeds were collected at Pastaza (Ecuador) in different urban gardens of Puyo and, after being photographed, the seeds were returned to their origin. Bismarckia nobilis: http://idtools.org/id/palms/palmid/factsheet.php?name=9401

- Figure 6: Serenoa repens: http://idtools.org/id/palms/palmid/factsheet.php?name=9457 Desmoncus sp.: Steven Paton, https://biogeodb.stri.si.edu/bioinformatics/dfm/metas/view/8262?\&lang=es Astrocaryum standleyanum: id. https://biogeodb.stri.si.edu/bioinformatics/dfm/metas/view/7546 Medemia argun: http://www.wellgrowhorti.com/Pictures/Palm\%20Seeds/Thumbnail/Medemia\% 20argun\%20seeds.jpg 
- Figure 7: Phoenix canariensis: Seed collection IRNASA-CSIC. Welfia regia: http://www.belizehank. com/IMAGES/Palm\%20Seeds/Palm\%20seeds\%20alphabetical/Welfia\%20regia.jpg Raphia taedigera: https://www.palmpedia.net/wiki/Raphia_taedigera

- Figure 8: Clinosperma macrocarpa: https://www.palmpedia.net/wiki/Clinosperma_macrocarpa Johannesteijsmannia altifrons: https://www.rarepalmseeds.com/johannesteijsmannia-altifrons Mauritia flexuosa: https://www.palmpedia.net/wiki/Mauritia_flexuosa

- Figure 9: Syagrus romanzoffiana: http://realpalmtrees.com/palm-tree-store/queen-palm-seedspkg.html Available also at: https://bit.ly/3lcvFNn Asterogyne martiana, from www.plant.ac.cn (zhiwutong.com). Aphandra natalia: collected at Pastaza (Ecuador) in different urban gardens of Puyo. After being photographed, the seeds were returned to their origin.

- Figure 10: Seeds were collected at Pastaza (Ecuador) in different urban gardens of Puyo and, after being photographed, the seeds were returned to their origin.

- $\quad$ Figure 11: Seed collection IRNASA-CSIC.

\section{References}

1. Dransfield, J.; Uhl, N.W.; Asmussen, C.B.; Baker, W.J.; Harley, M.M.; Lewis, C.E. Genera Palmarum: The Evolution and Classification of Palms; Kew Publishing, Royal Botanic Gardens of Kew: London, UK, 2008.

2. Von Humboldt, A. Personal Narrative of Travels to the Equinoctial Regions of the New Continent During the Years 1799-1804; Longman, Hurst, Rees, Orme and Brown: London, UK, 1829; Volume 5.2, pp. 727-729.

3. Hooker, W.J. Museum of Economic Botany: Or a Popular Guide to the Useful and Remarkable Products of the Museum of the Royal Gardens of Kew; Longman, Brown, Green and Longmans: London, UK, 1855.

4. Ribeiro Mendes, J.C.; de Sousa Portilho, A.J.; Andrade de Aguiar-Dias, A.C.; da Silva Sampaio, K.L.; de Nazaré Farias, L. Arecaceae: Uma estratégia diferenciada para o ensino de botânica em uma escola de ensino médio na ilha de Cotijuba, Pará, Brasil. In Enciclopédia Biosfera; Centro Científico Conhecer: Goiânia, Brasil, 2019; Volume 16, pp. 2226-2240.

5. Meerow, A.W. Arecaceae, the palm family. In The Encyclopedia of Fruits and Nuts; Janick, J., Paull, R.E., Eds.; CABI: Wallingford, UK; Cambridge, MA, USA, 2006.

6. Valencia, R.; Montufar, R.; Navarrete, H.; Balslev, H. Palmas Ecuatorianas: Biología y Uso Sostenible; Publicaciones del Herbario QCA de la Pontificia Universidad Católica del Ecuador: Quito, Ecuador, 2013.

7. Jácome, J.; Montúfar, R. Mocora. Astrocaryum standleyanum. In Palmas Ecuatorianas: Biología y Uso Sostenible; Valencia, R., Montufar, R., Navarrete, H., Balslev, H., Eds.; Publicaciones del Herbario QCA de la Pontificia Universidad Católica del Ecuador: Quito, Ecuador, 2013; pp. 99-101.

8. Henderson, A. Evolution and Ecology of Palms; The New York Botanical Garden Press: Bronx, NY, USA, 2002.

9. Gottsberger, G. Seed dispersal by fish in the inundated regions of Humaita, Amazonia. Biotropica 1978, 10, 170-183. [CrossRef]

10. Zona, S.; Henderson, A. A review of animal-mediated seed dispersal of palms. Selbyana 1989, 11, 6-21.

11. Cervantes, E.; Martín Gómez, J.J.; Gutiérrez del Pozo, D.; Silva Dias, L. An Angiosperm Species Dataset Reveals Relationships between Seed Size and Two-Dimensional Shape. Horticulturae 2019, 5, 71. [CrossRef]

12. Piedade, M.T.; Parolin, P.; Junk, W.J. Phenology, fruit production and seed dispersal of Astrocaryum jauari (Arecaceae) in Amazonian black water floodplains. Rev. Biol. Trop. 2006, 54, 1171-1178. [CrossRef]

13. Muñoz, G.; Trøjelsgaard, K.; Kissling, W.D. A synthesis of animal-mediated seed dispersal of palms reveals distinct biogeographical differences in species interactions. J. Biogeogr. 2019, 46, 466-484. [CrossRef]

14. Murray, S.G. The formation of endocarp in palm fruits. Principes 1973, 17, 91-102.

15. Henderson, F.M.; Stevenson, D.W. A phylogenetic study of Arecaceae based on seedling morphological and anatomical data. Aliso 2006, 22, 251-264. [CrossRef]

16. Rovner, I.; Gyulai, F. Computer-assisted morphometry: A new method for assessing and distinguishing morphological variation in wild and domestic seed populations. Econ. Bot. 2007, 61, 154-172. [CrossRef]

17. Sonka, M.; Hlavac, V.; Boyle, R. Image Processing Analysis and Machine Vision; Thomson: Stamford, CT, USA, 2008.

18. Zheng, Y.; Guo, B.; Chen, Z.; Li, C. A Fourier Descriptor of 2D Shapes Based on Multiscale Centroid Contour Distances Used in Object Recognition in Remote Sensing Images. Sensors 2019, 19, 486. [CrossRef] [PubMed] 
19. Cervantes, E.; Martín-Gómez, J.J.; Saadaoui, E. Updated Methods for Seed Shape Analysis. Scientifica 2016, 2016, 5691825. [CrossRef]

20. Cervantes, E.; Martín Gómez, J.J. Seed Shape Description and Quantification by Comparison with Geometric Models. Horticulturae 2019, 5, 60. [CrossRef]

21. Cervantes, E. Seed Morphology. Scholarly Community Encyclopedia. 2020. Available online: https: //encyclopedia.pub/item/revision/7894d28ff2ebed5217b9d81a23a8c84e (accessed on 6 October 2020).

22. Cervantes, E.; Martín, J.J.; Ardanuy, R.; de Diego, J.G.; Tocino, Á. Modeling the Arabidopsis seed shape by a cardioid: Efficacy of the adjustment with a scale change with factor equal to the Golden Ratio and analysis of seed shape in ethylene mutants. J. Plant Physiol. 2010, 67, 408-410. [CrossRef] [PubMed]

23. Cervantes, E.; Martín, J.J.; Chan, P.K.; Gresshoff, P.M.; Tocino, Á. Seed shape in model legumes: Approximation by a cardioid reveals differences in ethylene insensitive mutants of Lotus japonicus and Medicago truncatula. J. Plant Physiol. 2012, 169, 1359-1365. [CrossRef] [PubMed]

24. Saadaoui, E.; Martín Gómez, J.J.; Tlili, N.; Khaldi, A.; Cervantes, E. Effect of Climate in Seed Diversity of Wild Tunisian Rhus tripartita (Ucria) Grande. J. Adv. Biol. Biotechnol. 2017, 13, 1-10. [CrossRef]

25. Martín-Gómez, J.J.; Saadaoui, E.; Cervantes, E. Seed Shape of Castor Bean (Ricinus communis L.) Grown in Different Regions of Tunisia. JAERI 2016, 8, 1-11.

26. Saadaoui, E.; Martín, J.J.; Bouazizi, R.; Chokri, B.R.; Grira, M.; Saad, A.; Khouja, M.L.; Cervantes, E. Phenotypic variability and seed yield of Jatropha curcas L Introduced to Tunisia. Acta Bot. Mex. 2015, 110, 119-134. [CrossRef]

27. Martín-Gómez, J.J.; Gutiérrez del Pozo, D.; Ucchesu, M.; Bacchetta, G.; Cabello Sáenz de Santamaría, F.; Tocino, Á.; Cervantes, E. Seed Morphology in the Vitaceae Based on Geometric Models. Agronomy 2020, 10, 739. [CrossRef]

28. Martín-Gómez, J.J.; Gutiérrez del Pozo, D.; Cervantes, E. Seed shape quantification in the Malvaceae reveals cardioid-shaped seeds predominantly in herbs. Bot. Lith. 2019, 25, 21-31. [CrossRef]

29. Cervantes, E.; Martín-Gómez, J.J. Seed shape quantification in the order Cucurbitales. Mod. Phytomorphol. 2018, 12, 1-13. [CrossRef]

30. Martín-Gómez, J.J.; Rewicz, A.; Cervantes, E. Seed Shape Diversity in families of the Order Ranunculales. Phytotaxa 2019, 425, 193-207. [CrossRef]

31. Saadaoui, E.; Martín-Gómez, J.J.; Cervantes, E. Seed morphology in Tunisian wild populations of Capparis spinosa L. Acta Biol. Cracov. Bot. 2013, 55, 99-106.

32. Weisstein, E.W. Circle. From MathWorld-A Wolfram Web Resource. Available online: https://mathworld. wolfram.com/Circle.html (accessed on 24 June 2020).

33. Weisstein, E.W. Ellipse. From MathWorld-A Wolfram Web Resource. Available online: https://mathworld. wolfram.com/Ellipse.html (accessed on 24 June 2020).

34. Weisstein, E.W. Oval. From MathWorld-A Wolfram Web Resource. Available online: https://mathworld. wolfram.com/Oval.html (accessed on 24 June 2020).

35. Weisstein, E.W. Lemniscate. From MathWorld-A Wolfram Web Resource. Available online: https://mathworld. wolfram.com/Lemniscate.html (accessed on 24 June 2020).

36. Weisstein, E.W. Superellipse. From MathWorld-A Wolfram Web Resource. Available online: https://mathworld. wolfram.com/Superellipse.html (accessed on 24 June 2020).

37. Weisstein, E.W. Cardioid. From MathWorld-A Wolfram Web Resource. Available online: https://mathworld. wolfram.com/Cardioid.html (accessed on 24 June 2020).

38. Weisstein, E.W. Lens. From MathWorld-A Wolfram Web Resource. Available online: https://mathworld. wolfram.com/Lens.html (accessed on 24 June 2020).

39. Weisstein, E.W. Vesica Piscis. From MathWorld-A Wolfram Web Resource. Available online: https://mathworld. wolfram.com/VesicaPiscis.html (accessed on 24 June 2020).

40. Weisstein, E.W. Heart Curve. From MathWorld-A Wolfram Web Resource. Available online: http://mathworld. wolfram.com/HeartCurve.html (accessed on 24 June 2020).

41. Clasen, A.; Kesel, A.B. Microstructural Surface Properties of Drifting Seeds-A Model for Non-Toxic Antifouling Solutions. Biomimetics 2019, 4, 37. [CrossRef] [PubMed]

42. De Oliveira Viana, E. Pós-colheita de Sementes e Produção de Mudas de Copernicia. Ph.D. Thesis, Universidade Federal do Ceará, Fortaleza, Brazil, 2019. Available online: http://www.repositorio.ufc.br/handle/riufc/46681 (accessed on 30 July 2020). 
43. Dowe, J.L. A taxonomic account of Livistona R.Br. (Arecaceae). Gard. Bull. 2009, 60, 185-344.

44. De Mendonca, M.S.; de Oliveira, A.B.; de Araujo, M.G.P.; Araujo, L.M. Morpho-anatomy of the fruit and seed of Oenocarpus minor Mart. (Arecaceae). Rev. Bras. Sementes 2008, 30, 90-95. [CrossRef]

45. Santana Silva, R.; Monteiro Ribeiro, L.; Mercadante-Simões, M.O.; Ferreira Nunes, Y.R.; Nascimento Lopes, P.S. Seed structure and germination in buriti (Mauritia flexuosa), the Swamp palm. Flora 2014, 209, 674-685. [CrossRef]

46. Martín-Gómez, J.J.; Rewicz, A.; Rodríguez-Lorenzo, J.L.; Janoušek, B.; Cervantes, E. Seed morphology in Silene based on geometric models. Plants 2020. under review.

47. Bobrov, A.V.F.C.; Lorence, D.H.; Romanov, M.S.; Romanova, E.S. Fruit Development and Pericarp Structure in Nypa fruticans Wurmb (Arecaceae): A Comparison with Other Palms. Int. J. Plant Sci. 2012, 173, 751-766. [CrossRef]

48. Bellot, S.; Bayton, R.P.; Couvreur, T.L.P.; Dodsworth, S.; Eiserhardt, W.L.; Guignard, M.S.; Pritchard, H.W.; Roberts, L.; Toorop, P.E.; Baker, W.J. On the origin of giant seeds: The macroevolution of the double coconut (Lodoicea maldivica) and its relatives (Borasseae, Arecaceae). New Phytol. 2020. [CrossRef]

49. Wada, S.; Reed, B.M. Seed Coat Morphology Differentiates Blackberry Cultivars. J. Am. Pomol. Soc. 2010, 64, 152-161.

50. Ter Steege, H.; Henkel, T.W.; Helal, N.; Marimon, B.S.; Marimon-Junior, B.H.; Huth, A.; Groeneveld, J.; Sabatier, D.; de Souza Coelho, L.; de Andrade Lima Filho, D.; et al. Rarity of monodominance in hyperdiverse Amazonian forests. Sci. Rep. 2019, 9, 13822. [CrossRef]

51. Hubau, W.; De Mil, T.; Van den Bulcke, J.; Phillips, O.L.; Angoboy Ilondea, B.; Van Acker, J.; Sullivan, M.J.; Nsenga, L.; Toirambe, B.; Couralet, C.; et al. The persistence of carbon in the African forest understory. Nat. Plants 2019, 5, 133-140. [CrossRef] [PubMed]

52. Lewis, S.L.; Sonké, B.; Sunderland, T.; Begne, S.K.; Lopez-Gonzalez, G.; van der Heijden, G.M.F.; Phillips, O.L.; Affum-Baffoe, K.; Baker, T.R.; Banin, L.; et al. Above-ground biomass and structure of 260 African tropical forests. Philos. Trans. R. Soc. B Biol. Sci. 2013, 368, 20120295. [CrossRef] [PubMed]

53. Lopez-Gonzalez, G.; Lewis, S.L.; Burkitt, M.; Phillips, O.L. ForestPlots.net: A web application and research tool to manage and analyse tropical forest plot data. J. Veg. Sci. 2011, 22, 610-613. [CrossRef]

54. Muscarella, R.; Emilio, T.; Phillips, O.L.; Lewis, S.L.; Slik, F.; Baker, W.J.; Couvreur, T.L.; Eiserhardt, W.L.; Svenning, J.C.; Affum-Baffoe, K.; et al. The global abundance of tree palms. Glob. Ecol. Biogeogr. 2020, 29, 1495-1514. [CrossRef]

55. Morcote-Rios, G.; Bernal, R. Remains of palms (Palmae) at archaeological sites in the New World: A review. Bot. Rev. 2001, 67, 309-350. [CrossRef]

56. Tomlinson, P.B. The Structural Biology of Palms; Clarendon Press: Oxford, UK, 1990. 